Adaptive Radiations in the

Context of Macroevolutionary

Theory: A

Paleontological Perspective

by Bruce S. Lieberman

2012

This is the author's accepted manuscript version of the article, made available with the permission of the publisher. The original published version can be found at the link below.

Lieberman, Bruce S. 2012. "Adaptive radiations in the context of macroevolutionary theory: a paleontological perspective." Evolutionary Biology (39):181-191.

Published version: http://dx.doi.org/10.1007/s11692-012-9165-8

Terms of Use: http://www2.ku.edu/ scholar/docs/license.shtml 


\title{
Adaptive Radiations in the Context of Macroevolutionary Theory: A Paleontological Perspective
}

\author{
Bruce S. Lieberman \\ Department of Geology and Biodiversity Institute, University of Kansas, 1475 Jayhawk Blvd., \\ 120 Lindley Hall, Lawrence KS 66045, USA \\ e-mail: blieber@ku.edu
}

Phone: $785-864-2741$

Fax: 785-864-5276

Total \# of words: 


\begin{abstract}
Adaptive radiations are often invoked anytime clades show significant bursts of diversification, but it is important to not simply assume that any radiating clade constitutes an adaptive radiation. In addition, several highly relevant macroevolutionary concepts including the Turnover Pulse Hypothesis, the Effect Hypothesis, exaptation, and species selection, have not been considered in the adaptive radiations literature. Here, these concepts are integrated into the theory of evolutionary radiations in general, and adaptive radiations in particular, and different types of evolutionary radiations are identified, including geographic radiations. Special emphasis is placed on considering the role that abiotic as opposed to biotic factors may play in motivating diversification during evolutionary radiations. Further, recent paleontological data suggesting that rather than organismal adaptation it may be principally abiotic factors, such as climate change and a taxon's presence in a geographically complex region, that cause clades to diversify will be described. The fossil record, the source of the initial hallmark examples of adaptive radiation, now appears to show little concrete support for this phenomenon.
\end{abstract}

Keywords Adaptive radiation, Macroevolution, Geographic radiation, Species selection, Exaptation, Speciation

\title{
Introduction
}

One of the important areas of research in evolutionary biology involves studies aimed at gaining a deeper understanding of the phenomenon of adaptive radiations, and there is an extensive body 
of literature dealing with this subject (Osborn 1902; Huxley 1942; Mayr 1942; Simpson 1944, 1953; Eldredge and Gould 1972; Eldredge 1979, 1989; Stanley 1979; Eldredge and Cracraft 1980; Cracraft 1982; Gould 1990; Lieberman 1993; Givnish 1997; Vogler and Goldstein 1997; Futuyma 1998; Schluter 2000; Losos and Miles 2002; Grant and Grant 2008; Abe and Lieberman 2009, 2012; Losos 2009; Olson and Arroyo-Santos 2009; Rundell and Price 2009). By the same token, adaptive radiations have often been invoked whenever there are bursts of significant diversification in clades. The existence of the adaptation supposedly driving the radiation, however, is not always tested for, such that evidence may be lacking. Further, the causal link relating why the hypothesized adaptation should cause the excessive diversification in the first place is not generally demonstrated. In short, adaptive radiations are frequently invoked without detailed testing, and it is important to not simply assume that any radiating clade represents an adaptive radiation (Eldredge and Cracraft 1980; Cracraft 1982; Gould 1990; Gittenberger 1991; Lieberman 1993; Vogler and Goldstein 1997; Rundell and Price 2009). A strict, hypothesis testing framework is needed before an adaptive radiation can be identified. Demonstrating an adaptive radiation in fossil taxa can be especially problematic, as it is very hard to conduct the detailed functional tests necessary to document the existence of adaptations in long extinct populations. It is somewhat ironic, therefore, that it was the vertebrate paleontologist Henry Fairfield Osborn (Osborn 1902) who first coined the term "adaptive radiation" to describe the radiation of mammal orders in the Cenozoic.

Another aspect of the literature on adaptive radiations is that several highly relevant concepts in the area of macroevolutionary theory, including the Turnover Pulse Hypothesis, the Effect Hypothesis, species selection, and exaptation have not been considered. Further, data gathered by macroevolutionists focusing on what causes clades to diversify have not generally been 
incorporated into the adaptive radiations literature. In actuality, abundant evidence has been gathered to suggest that it may be principally abiotic factors, such as geologic change, climatic change, and a taxon's presence in a geographically complex region, which causes clades to undergo rampant diversification, rather than organismal adaptation. Further, even when there may be biotic factors driving diversification, these may not be organismal adaptations, but instead species-level characters that lead to a greater propensity for certain groups to speciate. The focus of this paper is on integrating concepts from macroevolution with the theory of adaptive radiations, and special emphasis is placed on studying evolutionary radiations in a macroevolutionary, hierarchical, and biogeographic context. Moreover, some results from recent paleontological research that may shed some light on the nature of evolutionary radiations will be described and emphasized.

\section{Defining what Constitutes an Adaptive Radiation}

Tempo and Mode and Natural Selection

In order to more explicitly consider evolutionary radiations in general, and adaptive radiations in particular, a two-dimensional space defining pattern, focused on the tempo of speciation, and process, focused on the role of selection, is defined for any clade (Fig. 1). (Although there has been debate about whether selection constitutes a pattern or a process, a topic considered specifically in reference to adaptive radiations by Cracraft 1982 and Vogler and Goldstein 1997, for our purposes here selection will be treated as a process, with the caveat that in certain contexts it should instead be referred to as a pattern.) Other axes/dimensions can be defined for 
clades, but since evolutionary tempo and selection (which pertains to adaptation) are such important aspects of the definition of adaptive radiation, these must be considered primary. Any clade might have a below average or above average rate of speciation relative to other clades, but clearly a clade must be radiating rapidly to potentially constitute an adaptive radiation. Thus, only clades occupying the right hand side of Figure 1 are even potentially germane to a discussion of adaptive radiations. Further, high rates of speciation should be quantified and considered in an hypothesis testing framework, and fortunately there are several methods that make this possible, e.g., Sanderson and Donoghue (1996), Lieberman (2001), and Nee (2006). Especially relevant as exponents of adaptive radiation are clades where selection is the primary factor spurring rapid diversification. Here it is argued that the term adaptive radiation should be restricted to clades occupying the lower right hand quadrant of Figure 1. However, simply identifying a clade that corresponds to the lower right hand quadrant of Figure 1 does not guarantee it constitutes an adaptive radiation. The selection spurring diversification may not be acting on an adaptation but instead on an exaptation. Thus, just as there are adaptive radiations, there can be "exaptive radiations," and these are discussed more fully below. Alternatively, the clade could be diversifying rapidly because of the action of selection, but not selection operating at the organism-level, but instead selection acting at the species-level. Such instances of species selection mediating evolutionary radiation are also considered herein. One additional aspect of selection worth qualifying in the context of evolutionary radiations is whether it is primarily biotically mediated or abiotically mediated. In particular, is it ecological interactions or environmental factors that enable the rapid diversification?

Of course, there can be clades that are rapidly radiating but where other factors instead of selection are involved. Such circumstances involve clades occupying the upper right hand 
quadrant of Figure 1. For instance, a clade could be diversifying rapidly because it occupies a geographically complex region, or because it has been buffeted by a series of geologic or climatic changes. Neither of these circumstances precludes the action of natural selection: natural selection must operate because it is a statistical law. However, in neither case is natural selection the primary factor that is motivating diversification. Therefore, it would be factually inaccurate to refer to such examples as adaptive radiations. Instead, here they are referred to as "geographic radiations," and they are discussed more fully below. Clades undergoing geographic radiation represent an interesting and important type of evolutionary radiation. Many clades once thought to be undergoing adaptive radiation might actually comprise geographic radiations, and be consigned to the upper right hand quadrant of Figure 1.

Adaptations, Exaptations, and Exaptive Radiations

Not every character currently subject to natural selection is an adaptation. There are many characters that evolved under one selective regime and later came to serve a different function and then subsequently came under another selective regime. That there was a distinction between these characters and traditional adaptations was first hinted at by Gould and Lewontin (1979) and then discussed in detail by Gould and Vrba (1982). Gould and Vrba (1982) referred to characters where the historical origin of the character vis à vis selection was different from its current utility as exaptations. Gould and Vrba (1982) further characterized adaptations and exaptations as each an exponent of a broader category - aptation. Pertinent to a discussion of evolutionary radiations, in cases exaptations rather than adaptations may have spurred subsequent rapid diversification. These cases should be properly defined as exaptive radiations 
to differentiate them from truly adaptive radiations. Further, some times because evolutionary radiations began in the distant past, or even constitute extinct clades frozen in the fossil record, it may be difficult to prove whether such instances truly represent exaptive as opposed to adaptive radiations. Thus the term "aptive radiation" may be the most accurate and theory neutral appellation to give to clades occupying the lower right hand quadrant of Figure 1, until such time as the character(s) in question posited to be spurring diversification can be shown to be adaptations, as opposed to exaptations. To fully document adaptation, and thereby demonstrate that an aptive radiation is indeed adaptive, detailed functional and phylogenetic tests are necessary. If it can be shown that the character in question posited to be responsible for the diversification of the clade had been continually shaped by natural selection for just such a purpose then it is fair to say that we are dealing with an adaptive radiation. Because of the nature of the paleontological record, the term aptive radiation is especially relevant for fossil taxa, as demonstrating adaptations in these is a particularly thorny problem.

It is possible that some clades once thought to constitute adaptive radiations might instead be exaptive radiations. Consider horses, one of the hallmark examples of adaptive radiation documented extensively in Simpson $(1944,1953)$. Simpson (1944) discussed how horses developed a character, hypsodonty (high-crowned teeth), which initially was pre-adaptive in his parlance, i.e., the character evolved due to genetic drift or selection for something else, perhaps selection for larger body-size during climatic cooling. It later came under selection for feeding habit, and ultimately facilitated a move by horses from a browsing to a grazing lifestyle. If the evolution of hypsodonty was first associated with selection for large body size and only later associated with a change in feeding (i.e., Wang et al. 1994), then hypsodonty would represent a 
patent example of an exaptation, and the diversification of horses would represent an exaptive radiation. Further, without the climate change, the radiation never would have happened.

Levels of Selection and Evolutionary Radiations

The debate about the importance of species selection has been extensive and fascinating, and considering it in detail would be beyond the scope of this paper, so the interested reader is referred to Vrba (1984, 1989), Vrba and Eldredge (1984), Eldredge (1985, 1989), Jablonski (1986, 2007), Lieberman et al. (1993), Lieberman and Vrba (1995, 2005), Gould (2002) and the references therein for more detailed discussion. It is clear from these and other studies that there are certain properties, emergent at the species-level, which cause clades to undergo rapid speciation. For instance, dispersal capabilities that influence population genetic structure, and variability within species, constitute such emergent properties (Vrba and Eldredge 1984; Jablonski 1986; Vrba 1989; Lieberman and Vrba 2005). If there are clades with these emergent properties that show a concomitant increase in the rate of speciation then they embody legitimate examples of species selection, and they also occupy the lower right hand quadrant of Figure 1 (they are radiating and selection is the cause). Yet a perspective that assumes all diversification is driven by organismic adaptation might mistakenly treat such clades as undergoing adaptive radiation. It is worth considering how clades experiencing species selection should be viewed in the adaptive radiations framework.

Characters emergent at the species-level are not adaptations (Lieberman and Vrba 1995) as they did not evolve nor are they maintained for the purposes of promoting high diversification rates. They are instead side consequences and hitchhike as properties relating to or dependent on 
some other features. Thus, they are exaptations. Clades undergoing species selection represent an important higher-level example of the exaptive radiations already mentioned, and are here referred to as "species-level exaptive radiations."

One recent example that may partially fit the pattern of a species-level exaptive radiation comes from the work of Moyle et al. (2009) on birds within the genus Zosterops. Moyle et al. (2009) described how this group did not show the characteristic ecomorphological signature predicted for a biotically driven adaptive radiation (discussed more fully below), yet had a high diversification rate. Further, correlated with this were certain properties that might influence population genetic structure and enhance propensity to speciate, and thereby be emergent at the species level. This includes aspects of their dispersal ability, intraspecific variability, and social structures.

The Effect Hypothesis.- Particularly germane here is consideration of Vrba's Effect Hypothesis (Vrba 1984, 1989). Vrba $(1984,1989)$ framed her discussion of the Effect Hypothesis using a specific example from bovids. She analyzed diversification patterns in the group, and specifically focused on one clade's differential predilection to produce new species through time relative to a closely related taxon. She concluded that this increase in net diversification rate was not due to species selection, but rather arose because organisms within the group were specialists and more likely to be subjected to directional natural selection during times of climate change (Vrba 1984, 1989). That is, the species sorting within the group (Vrba and Gould 1986; Lieberman and Vrba 1995) was due to organism-level natural selection. Further, this arose as a side consequence of another trait (one clade consists of specialists, the other of generalists). Vrba's (1984) example of the Effect Hypothesis appears to constitute a legitimate example of an exaptive radiation because there is an increase in speciation rate driven by natural selection. 


\section{Abiotic and Biotic Factors and Exaptive and Adaptive Radiations}

Another important aspect of the discussion of the role of selection in adaptive and exaptive radiations is considering whether it is primarily biotic or abiotic factors that caused the selection. For this reason, the realm of the adaptive and exaptive radiation, the lower right hand quadrant of Figure 1, can be further partitioned as in Figure 2, based on the role that biotic factors, including competition, as opposed to abiotic factors, including climatic change, played in mediating the selection pressure that led to diversification.

Consider the case of Vrba's Effect Hypothesis just mentioned. There, the bovid radiation was mediated by interactions between the abiotic environment and biotic attributes of organisms. Thus, there is a distinctly abiotic flavor to this exaptive radiation, for without the environmental change the radiation would not have transpired. Probably the example from horses already mentioned also was primarily driven by abiotic factors.

By contrast, in cases where species selection is occurring, there clearly are biotic factors that are ramping up diversification rates, such that any time there is a species-level exaptive radiation, it was produced by biotic factors (see Fig. 2). Returning to the example from Moyle et al. (2009), as already mentioned above, aspects of that radiation fit the pattern of a species-level exaptive radiation. Intriguingly, there are also aspects of the Zosterops radiation consonant with an exaptive radiation mediated by Vrba's Effect Hypothesis, because selection operating at the organism level may have helped to foment the radiation. Unlike the example from Vrba's bovids, however, there is a more distinctly biotic flavor to this aspect of the radiation. In particular, several species of Zosterops have short generation times (Moyle et al. 2009), 
suggesting that individual organisms within the group may be able to respond rapidly to the action of natural selection. In this case it is not changes in the abiotic environment that are triggering the directional selection. Instead, it is the presence of distinct food sources these birds may encounter on new islands, and thus biotic factors. This points out the fascinating and complex nature of evolutionary radiations, for within any given clade more than one cause may explain the radiation, and perhaps even within any given clade there may be more than one radiation.

Adaptive radiations mediated by abiotic factors, especially climate change, are likely to be important, although these have received less attention in the scientific literature. By contrast, there have been several treatments of adaptive radiations detailing how biotic factors such as ecological interactions or entering a new region, adaptive zone, or ecospace can spur diversification (e.g., Givnish1997; Schluter 2000; Losos 2009; Rundell and Price 2009; Yoder et al. 2010). Since paleontological evidence for this type of radiation seems anecdotal, or at times even illusory (the views of Osborn 1902 and Simpson 1953 not withstanding), it will not be the principal focus herein. However, because of its centrality in several discussions of adaptive radiations, some discussion is warranted. One consistently invoked litmus test for these types of radiation is the ability to recover a pattern of morphological and ecological, or ecomorphological (Ricklefs and Miles 1994) divergence, which involves demonstrating that phenotypes and environments/ecology are closely related, sometimes using morphometric evidence (Harmon et al. 2003, 2010). These radiations are treated herein as principally being caused by biotic factors (Fig. 2). Scientific evidence to affirm this type of radiation includes the ability to invoke newly available lifestyles or landscapes, the acquisition of key characteristics, some significant ecological interactions between radiating taxa, and also to document some evidence for 
sympatric speciation. The fact that speciation is typically allopatric (geographic) and not sympatric (ecological) is significant, and is discussed more fully below.

Abe and Lieberman (2012) used morphometric methods to study patterns of morphological diversification across phylogenetic space in a group of Devonian trilobites, the calmoniids. These have often been treated as a classic example of an adaptive radiation (see discussion in Eldredge and Cracraft 1980, Lieberman et al. 1991, and Lieberman 1993). Abe and Lieberman (2012) found that there was no statistical difference in the amount of morphological change that occurred when speciation was either sympatric or allopatric, nor did the amount of morphological change at speciation decline through time and with cladistic rank as the clade became more diverse. Thus, any stamp of ecological interaction and ecomorphological divergence is lacking, and it appears that the calmoniids were not undergoing an adaptive radiation mediated by biotic factors (the type of evolutionary radiation the calmoniids appear to comprise is discussed more fully below). It is of course difficult to know at this time the extent to which this example is characteristic of other evolutionary radiations in general, and those preserved in the fossil record in particular. Certainly there are several examples based on studies of extant taxa that indicate adaptive radiations caused by biotic factors are important phenomena, but the evidence for these types of radiations in the fossil record does seem to be quite narrowly circumscribed. The paucity of paleontological examples of these types of radiations may find explanation in an important perspective introduced by Rundell and Price (2009), who argued that in older radiations the signature of ecologically fueled differentiation characteristic of biotically driven adaptive radiations could get effaced. This is because closely related, sympatric species often tend to merge and have only an ephemeral existence, especially when they experience climate change. This perspective is especially apposite when considering radiations preserved in 
the fossil record: such radiating clades perforce require an ample amount of time to become established so that they can become manifest to paleontologist's. Another issue is that the cryptic or nearly cryptic species often produced in the early phases of biotically driven adaptive radiations by definition cannot be discerned in the fossil record, and thus any diversity produced by such radiations might be paleontologically invisible.

\section{Geographic Radiations}

Although demonstrable examples of biotically mediated adaptive radiation seem few and far between in the fossil record, this is not to suggest that evolutionary radiations themselves are rare in the fossil record: indeed, they are quite commonplace. Such radiations typically seem to comprise clades occupying the space in the upper right hand quadrant of Figure 1. Sometimes such clades have been mistakenly treated as epitomizing adaptive radiation, but the primary factor motivating diversification is not natural selection. Discussing this issue requires some consideration of speciation mode. Of course sympatric speciation, which is ecologically driven, provides a direct connection between speciation and the phenomenon of adaptive radiation. It is now clear, however, that speciation is transcendently allopatric, perhaps even in clades that are typically held up as examples of adaptive radiation (Glor et al. 2004). What if climate change or geological change is responsible for triggering an evolutionary radiation by triggering bouts of

allopatric speciation? Evidence is accumulating to suggest that some of the classic examples of adaptive radiation may primarily have been produced by speciation operating in the standard allopatric mode. It would seem somewhat inaccurate to refer to evolutionary radiations triggererd by allopatric speciation in a geographically complex region as adaptive radiations. 
Certainly islands biotas comprise a significant proportion of the examples of so called adaptive radiations, and islands undoubtedly qualify as geographically complex regions. Given that speciation typically occurs in the allopatric mode, it is very likely that a clade's presence in such a region will amplify opportunities for diversification. We might suspect that the most spectacular examples of diversification involve clade's that possess biotic characteristics that make them likely to diversify, perhaps emergent properties of species, that also occupy a geographically complex region. For instance, birds possess distinctive dispersal capabilities that could influence population genetic structure, and they are one type of taxon that especially seems to proliferate once they arrive on islands. Cadena et al. (2005), Emerson and Kolm (2005), and Whittaker et al. (2007) do also provide interesting recent treatments and discussions of some of the ecological phenomena associated with islands that might make them cradles of diversity.

A paleontological example of how geographic complexity can be the arbiter for where and why radiations happen comes from the work of Abe and Lieberman (2009). Using phylogenetic biogeographic analysis and also evolutionary rate studies they documented how the patterns of diversification in the calmoniid trilobites, the aforementioned classic example of an adaptive radiation, seem to be related to the fact that the group occurred in a geologically complex region that consisted of several distinct marine basins that were not always connected. Overlaid over this complex topography there were repeated episodes of climate change that caused oscillations in sea-level that would join and later sunder marine connections between the basins (remove and then reinstate geographic barriers), allowing and then restricting opportunities for movement between the basins by trilobite taxa. This provided for repeated episodes of range expansion followed by allopatric differentiation and speciation (Abe and Lieberman 2009). Allopatric differentiation following isolation might involve a combination of adaptive and non-adaptive 
mechanisms (including drift) so at least in one sense the calmoniid radiation is not without any adaptive character. However, the intiating factors that precipitated the radiation were geological and climatic (Abe and Lieberman 2009). Moreover, as already described above, there does not seem to be the characteristic signature of morphological divergence across phylogenetic space in the calmoniids that one would associate with the existence of prominent ecological interactions between species (Abe and Lieberman 2012). Thus, it would be theoretically murky and inaccurate to refer to the calmoniid diversification as an adaptive radiation. Rundell and Price (2009) described other examples that seem to match the pattern found in the calmoniids.

Cracraft (1982) and Gittenberger (1991) provided a very useful discussion of how opportunities for allopatry can stimulate diversification. Gittenberger (1991) further argued that clades diversifying because of extensive opportunities for allopatry should be treated as undergoing "non-adaptive radiation." He held that non-adaptive radiations were especially likely to prevail and should be invoked when there is no profound role for biotic factors driving diversification. Rundell and Price (2009) reiterated and supported this perspective and Losos and Glor (2003) also discussed some of the issues pertaining to considering divergence mechanisms in the context of speciation. Gittenberger's (1991) observations seem fundamental, yet there might be some concern with applying the term non-adaptive radiation to the calmoniid trilobite radiation (and possibly other radiations), as the clade persisted for tens of millions of years: in at least a trivial sense the clade must have been adapted, so that descriptor could perhaps be rejected by some as potentially inaccurate or confusing. Further, some differentiation in allopatry, even if that particular aspect of differentiation did not cause the radiation, can still have an adaptive character. However, the treatment herein very much endorses the perspective that Gittenberger (1991) brought to the discussion of these radiations, as it is not adaptation that 
is causing the profound divergence. Instead, the term "geographic radiation" is offered to best describe the situation found in these calmoniid trilobites. Further, any time a geographic radiation occurs, it is fundamentally being driven by abiotic factors.

Interestingly, in the calmoniid trilobites, just as it was geographic complexity that spurred the radiation of the group, it was the demise of such complexity that ultimately terminated the radiation. In particular, during the Devonian there were repeated episodes of sea-level rise and fall, but generally sea-level was on the rise. At some point in the Devonian sea-level rose sufficiently to the point where even during the oscillations that precipitated a drawdown in sealevel, sea-level was still high enough to ensure largely continuous marine connections between the once isolated, distinct marine basins in the region (Abe and Lieberman 2009, 2012). In a sense, the climatic changes ultimately trumped the geological factors that had made the region the trilobites occupied once so complex, and opportunities for allopatric differentiation diminished. Ultimately the speciation faucet was shut off and the group ceased radiating, with speciation rate falling to zero. In the face of continual, low to moderate extinction rates, the group basically faded away over the course of a few millions of years.

Paradoxically perhaps, since it is often offered as such a paradigm example of the adaptive radiation phenomenon, aspects of the radiation of Galapagos Finches may match the pattern found in the trilobites. Certainly there are many fascinating patterns associated with the radiation, which has been studied in detail over the course of many years (see Grant and Grant 2008). However, consider that the bulk of speciation in the group seems to be allopatric and further that the Galapagos finches are not monophyletic: one species within the group is found in Cocos Island, some $800 \mathrm{~km}$ northeast of the Galapagos Island chain (Grant and Grant 2008). Like its Galapagos kin, this species has diverse feeding behaviors, yet there has not been a 
corresponding radiation of Cocos finches. This suggests that there may have been something about the Galapagos and the fact that it was a relatively geographically complex island chain that facilitated the radiation of the finches there (Abe 2010).

Different types of Allopatric Speciation and Further Characterizing Geographic Radiations

One additional aspect of geographic radiations worth considering has to do with the fact that there are two primary types of allopatric speciation relevant to discussions dealing with fossil taxa: vicariance and peripatric or peripheral isolates speciation (Wiley and Mayden 1985; Brooks and McLennan 1991; Lieberman 2000; Wiley and Lieberman 2011). When speciation occurs via vicariance species are not expanding their ranges by dispersing over pre-existing barriers (although their ranges may expand up to the limit of those barriers). Instead, barriers emerge within pre-existing ranges, thereby subdividing them. By contrast, with peripatric speciation, organisms are actively dispersing over pre-existing barriers. With vicariance, an important component of the work involved with proximally causing speciation is done by geology and climate and the organisms are more languorous. With peripatry, organisms are providing an important component of the action, although of course the geological or climatic barriers must have been produced previously and are still some of the important ultimate causes of speciation (Lieberman 2000).

The example from the calmoniids already discussed seems to principally involve vicariance (Abe and Lieberman 2009, 2012): species are not actively dispersing over pre-existing barriers. Instead, the episodes of sea-level rise and fall are causing more passive range expansion. By contrast, certain examples of geographic radiation within island chains, especially involving 
birds, are more likely to have involved peripatric speciation and thus more active dispersal by component taxa (Mayr 1942; Grant and Grant 2008). When information about the dominant type of allopatric speciation driving a geographic radiation is available, it may be worth providing additional qualifiers for geographic radiations: geographic radiations spurred by vicariance can be referred to as "vicariant geographic radiations;" those spurred by peripatry can be referred to as "peripatric geographic radiations." At this time not enough is known about the relative proportions of either of these to ascertain whether vicariant geographic radiations or peripatric geographic radiations are numerically more dominant. It is even conceivable that many geographic radiations may include episodes of both vicariance and peripatry, such that it would not always be possible to further parse geographic radiations into sub-categories, but the example from the calmoniids appears to comprise a legitimate vicariance geographic radiation.

\section{Evolutionary Radiations and Monophyly}

These discussions have principally focused on evolutionary radiations in the context of single clades, but another aspect of defining these radiations is considering whether the term should be restricted to a single, monophyletic clade, as Eldredge and Cracraft (1980) argued (see also Givnish 1997; Abe 2010), or rather whether the term should encompass several different clades simultaneously radiating. In point of fact, Osborn (1902), the architect of the term adaptive radiation, distinguished between "general adaptive radiations" which would circumscribe several coevally radiating clades and "local adaptive radiations" which in today's parlance would be restricted to a single clade. Focusing on general radiations and not considering whether they might be adaptive or not, examples would include the Cambrian radiation, which is the 
proliferation of bilaterian animals at the end of the Proterozoic and start of the Phanerozoic (Lieberman 2003), and the aforementioned Cenozoic radiation of mammals. Whether the primary force driving these radiations was generally ecological factors and adaptation is still debated, but here the perspective is suggested that applying the term general adaptive radiation is too imprecise: in reality, probably what is transpiring during the Cambrian radiation is several, separate radiations occurring in several phyla (and even classes, etc.). These may, or may not, have been driven by the same process, and further, there is little evidence that adaptation played a paramount role (Lieberman 2003). Another instructive instance comes from cichlids, which have undergone separate monophyletic radiations in several different African lakes (Kocher 2004; Seehausen 2006; Abe 2010), yet there is no one cichlid, or even African cichlid, adaptive radiation.

The Turnover Pulse Hypothesis

One other excellent example of a phenomenon that has relevance to the discussion of evolutionary radiations in general and the question of monophyly in particular is Vrba's Turnover Pulse Hypothesis (Vrba 1985, 1992). She defined Turnover Pulse's as involving episodes of climatic change that caused geographic isolation in various taxa; the isolation subsequently spurred extinction and speciation in several different clades. Vrba's paradigm examples came from several clades of Plio-Pleistocene tropical mammals including suids, bovids, and hominids, but examples have since come from taxa as far afield as Devonian trilobites (Lieberman 1999). In a sense, each set of the clades radiating during a Turnover Pulse comprises a separate, independent instance of a geographic radiation. The mechanism behind 
these radiations is an Earth history phenomenon, climate change, which spurs allopatric speciation. The Turnover Pulse Hypothesis is significant because it extends the geographic radiation concept from a single to a multi-clade context.

In a sense, showing that several separate clades are radiating during a commonly experienced episode of climate change is powerful evidence that it is not the individualistic, biotic characteristics of each of these clades that is spurring the diversification, but rather the common Earth history factors. Indeed, this signifies the important connection between the Turnover Pulse Hypothesis and phylogenetic biogeography, where the emphasis is on identifying biogeographic congruence, similarities in patterns of evolution across geographic space, in several different clades (Wiley 1981; Brooks and McLennan 1991; Lieberman 2000; Morrone 2008; Wiley and Lieberman 2011). Such congruence can be attributed to a common causal factor, either geological change or climatic change, which triggers vicariant speciation. Thus, episodes of Turnover Pulse can be treated as vicariant geographic radiations.

Mass Extinctions and Evolutionary Radiations

Mass extinction is another important paleontological phenomenon particularly relevant to discussions of evolutionary radiations and monophyly. For instance, consider the aforementioned Cenozoic radiation of mammals after the end Cretaceous mass extinction. This episode of rampant diversification following the mass extinction, and other episodes of diversification after other mass extinctions, has been anecdotally referred to as adaptive radiations, but in the case of the mammals what is transpiring actually seems to comprise several separate radiations. Moreover, these types of radiations have been attributed to the creation of 
open ecospace and the relaxation of selection pressures. Although it is easy to understand how the survivors of such an event might be ecologically successful, with the number of organisms within any of the surviving species growing precipitously in the face of propitious ecological conditions, it is harder to see how that organismic success translates to the diversification of species (Yoder et al. 2010), especially if one takes an explicitly hierarchical view of nature (Vrba

and Eldredge 1984; Eldredge 1985, 1989; Gould 1990, 2002; Benton 1996; Lieberman 2000).

At this time it is clear that bouts of diversification do follow mass extinctions, but it is harder to understand the precise evolutionary mechanisms why, especially when thinking in a macroevolutionary context. One possibility though is that perhaps the survivor species have become so fragmented into small, isolated populations that multiple episodes of allopatric speciation ensue (E. Wiley, pers. comm.).

\section{Conclusions}

Adaptive radiations have rightly been recognized as an important topic in evolutionary biology, but sometimes a variety of different patterns and processes have been subsumed under the term adaptive radiation. In order to more fully understand the various phenomena that generically have been called adaptive radiation, it is critical to distinguish the causal factors responsible, especially the role of selection processes both at the organism and species level, the relative contribution of biotic and abiotic factors, and also to determine whether the characters involved are adaptations or exaptations. In reality, several different types of radiating clades exist running the gamut from those undergoing geographic radiation, where adaptation is not playing the primary role in motivating diversification, to those undergoing biotically driven adaptive 
radiation, the classic style of adaptive radiation replete with evidence of ecomorphological divergence, and finally to those undergoing species-level exaptive radiation where species selection explains the diversification. At least in the fossil record, ironically the source of the initial hallmark examples of adaptive radiation, it now seems that patent evidence for adaptive radiation driven by biotic factors is likely very restricted. Instead, the fossil record seems a better exponent of geographic radiation and other styles of abiotically mediated radiation including abiotically driven exaptive radiations. Perhaps this is not surprising given that the history of life is ultimately a drama preserving the interaction between our planet's biota and the various abiotic impulses it has been subjected to, including climatic and geologic change (Lieberman 2000). Further, in the fossil record competitive factors seem to have left less of an imprint, at least at the macroevolutionary scale (Benton 1996; Myers and Lieberman 2011). Ultimately, our understanding of evolutionary radiations will continue to advance as scientists better characterize the patterns they are studying and more fully grasp the processes generating them.

Acknowledgments Thanks to Maria Pia Miglietta, Francesco Santini, and Anuschka Faucci for inviting me to participate in this special issue of the journal. Thanks to Francine Abe and Ed Wiley for discussions on the subject of adaptive radiations. This research was supported by NSF-DEB-0716162.

\section{References}

Abe FR. 2010. The Nature of Evolutionary Radiations with a Special Focus on Devonian Calmoniid Trilobites. Ph.D. Dissertation, University of Kansas. 
Abe FR, Lieberman BS. 2009. The nature of evolutionary radiations: A case study involving Devonian trilobites. Evolutionary Biology 36:225-234.

Abe FR, Lieberman BS. 2012. Quantifying morphological change during an evolutionary radiation of Devonian trilobites. Paleobiology. In press.

Benton MJ. 1996. Testing the roles of competition and expansion in tetrapod evolution. Proceedings of the Royal Society of London, Biological Sciences, Series B 263:641-646.

Brooks DR, McLennan DA. 1991. Phylogeny, Ecology, and Behavior. Chicago: University of Chicago Press.

Cadena CD, Ricklefs RE, Jiménez I, Bermingham E. 2005. Ecology” is speciation driven by species diversity? Nature 438:E1-E2.

Cracraft J. 1982. A nonequilibrium theory for the rate-control of speciation and extinction and the origin of macroevolutionary patterns. Systematic Zoology 31:348-365.

Eldredge N. 1979. Alternative approaches to evolutionary theory. Bulletin of Carnegie Museum of Natural History 13:7-19.

Eldredge N. 1985. Unfinished Synthesis. New York: Oxford University Press.

Eldredge N. 1989. Macroevolutionary Dynamics. New York: McGraw-Hill.

Eldredge N, Gould SJ. 1972. Punctuated equilibrium: an alternative to phyletic gradualism. In: Schopf TJM, editor. Models in Paleobiology. San Francisco: W. H. Freeman. p. 82-115. Eldredge N, Cracraft J. 1980. Phylogenetic Patterns and the Evolutionary Process: Method and Theory in Comparative Biology. New York: Columbia University Press.

Emerson BC, Kolm N. 2005. Species diversity can drive speciation. Nature 434:1015-1017.

Futuyma DJ. 1998. Evolutionary Biology, $3^{\text {rd }}$ edition. Sunderland, MA: Sinauer.

Gittenberger E. 1991. What about non-adaptive radiation? Biological Journal of the Linnean 
Society 43:263-272.

Givnish TJ. 1997. Adaptive radiation and molecular systematics: issues and approaches. In:

Givnish TJ, Sytsma KJ, editors. Molecular Evolution and Adaptive Radiation. Cambridge:

Cambridge University Press. p. 1-54.

Glor RE, Gifford ME, Larson A, Losos JB, Rodriguez-Schettino L, Lara ARC, Jackman TR. 2004. Partial island submergence and speciation in an adaptive radiation: a multilocus analysis of the Cuban green anoles. Proceedings of the Royal Society, Biological Sciences, Series B 271(1554):2257-2265.

Gould SJ. 1990. Speciation and sorting as the source of evolutionary trends, or 'things are seldom what they seem.' In: McNamara, KJ, editor. Evolutionary Trends. London: Belhaven Press. P. 3-27.

Gould SJ. 2002. The Structure of Evolutionary Theory. Cambridge, MA: Harvard University Press.

Gould SJ, Lewontin RC. 1979. The spandrels of San Marco and the Panglossian paradigm: a critique of the adaptationist programme. Proceedings of the Royal Society of London, Series B, 205(1161):581-598.

Gould SJ, Vrba ES. 1982. Exaptation - a missing term in the science of form. Paleobiology 8:415.

Grant PR, Grant BR. 2008. How and Why Species Multiply: The Radiation of Darwin's Finches. Princeton, NJ: Princeton University Press.

Harmon LJ, Schulte JA II, Larson A, Losos JB. 2003. Tempo and mode of evolutionary radiation in iguanian lizards. Science 301(5635):961-964. 
Harmon LJ, Losos JB, Davies, TJ, Gillespie RG, Gittleman JL, Jennings WB, Kozak KH, McPeek MA, Moreno-Roark F, Near TJ, Purvis A, Ricklefs RE, Schluter D, Schulte JA II, Seehausen O, Sidlauskas BL, Torres-Carvajal O, Weir JT, Mooers AO. 2010. Early bursts of body size and shape evolution are rare in comparative data. Evolution 64:2385-2396.

Huxley J. 1942. Evolution: The Modern Synthesis. London: Allen \& Unwin.

Jablonski D. 1986. Larval ecology and macroevolution of marine invertebrates. Bulletin of Marine Science 39:565-587.

Jablonski D. 2007. Scale and hierarchy in macroevolution. Palaeontology 50:87-109.

Kocher TD. 2004. Adaptive evolution and explosive speciation: the cichlid model. Nature Genetics 5:288-298.

Lieberman BS. 1993. Systematics and biogeography of the "Metacryphaeus Group" Calmoniidae (Trilobita, Devonian) with comments on adaptive radiations and the geological history of the Malvinokaffric realm. Journal of Paleontology 67:549-570.

Lieberman BS. 1999. Turnover pulse in trilobites during the Acadian Orogeny. Proceedings of the Appalachian Biogeography Symposium. Virginia Museum of Natural History Special Publications Number 7:99-108.

Lieberman BS. 2000. Paleobiogeography. New York: Kluwer Academic Publishers.

Lieberman BS. 2001. A test of whether rates of speciation were unusually high during the Cambrian radiation. Proceedings of the Royal Society, Biological Sciences, Series B 268:1707-1714.

Lieberman BS. 2003. Taking the pulse of the Cambrian radiation. Journal of Integrative and Comparative Biology 43:229-237. 
Lieberman BS, Vrba ES. 1995. Hierarchy theory, selection, and sorting. Bioscience 45(6):394-399.

Lieberman BS, Vrba ES. 2005. Stephen Jay Gould on species selection: 30 years of insight. Paleobiology 31(2, supplement):113-121.

Lieberman BS, Allmon WD, Eldredge N. 1993. Levels of selection and macroevolutionary patterns in the turritellid gastropods. Paleobiology 19:205-215.

Lieberman BS, Edgecombe GD, Eldredge N. 1991. Systematics and biogeography of the “Malvinella Group”, Calmoniidae (Trilobita, Devonian). Journal of Paleontology $65: 824-843$.

Losos JB. 2009. Lizards in an evolutionary tree: ecology and adaptive radiation of anoles. University of California Press, Berkeley, CA.

Losos JB, Glor RE. 2003. Phylogenetic comparative methods and the geography of speciation. Trends in Ecology and Evolution 18:220-227.

Losos JB, Miles DB. 2002. Testing the hypothesis that a clade has adaptively radiated: iguanid lizard clades as a case study. American Naturalist 160:147-157.

Mayr E. 1942. Systematics and the Origin of Species. New York: Columbia University Press.

Morrone JJ. 2008. Evolutionary Biogeography: An Integrative Approach with Case Studies. New York: Columbia University Press.

Moyle RG, Filardi CE, Smith CF, Diamond J. 2009. Explosive Pleistocene diversification and hemispheric expansion of a "great speciator." Proceedings of the National Academy of Sciences, U.S.A. 106(6):1863-1868. 
Myers C, Lieberman BS. 2011. Sharks that pass in the night: Using GIS to investigate competition in the Cretaceous Western Interior Seaway. Proceedings of the Royal Society, Biological Sciences, Series B. 278(1706):681-689.

Nee S. 2006. Birth-death models in macroevolution. Annual Review of Ecology, Evolution and Systematics 37:1-17.

Olson ME, Arroyo-Santos A. 2009. Thinking in continua: beyond the 'adaptive radiation' metaphor. Bioessays 31(12):1337-1346.

Osborn H. 1902. The law of adaptive radiation. American Naturalist 36:353-363.

Ricklefs RE, Miles DB. 1994. Ecological and evolutionary inferences from morphology: an ecological perspective. In: Wainwright PC, Reilly SM, editors. Ecological Morphology: Integrative Organismal Biology. Chicago: University of Chicago Press. P. 13-41.

Rundell RJ, Price TD. 2009. Adaptive radiation, nonadaptive radiation, ecological speciation and nonecological speciation. Trends in Ecology \& Evolution 24(7):394-399.

Sanderson M, Donoghue M. 1996. Reconstructing shifts in diversification rates on phylogenetic trees. Trends in Ecology \& Evolution 11:15-20.

Schluter D. 2000. The Ecology of Adaptive Radiation. Oxford: Oxford University Press. Seehausen O. 2006. African cichlid fish: a model system in adaptive radiation research. Proceedings of the Royal Society, Biological Sciences, Series B 273 (1597):1987-1998. Simpson GG. 1944. Tempo and Mode in Evolution. New York: Columbia University Press. Simpson GG. 1953. The Major Features of Evolution. New York: Columbia University Press. Stanley SM. 1979. Macroevolution, Pattern and Process. San Francisco: W. H. Freeman. Vogler A, Goldstein P. 1997. Adaptive radiation and taxon cycles in North American tiger beetles: A cladistic perspective. In: Givnish TJ, Sytsma KJ, editors. Molecular evolution 
and adaptive radiation. Cambridge: Cambridge University Press. p. 353-373.

Vrba ES. 1980. Evolution, species and fossils: How does life evolve? South African Journal of Science 76:61-84.

Vrba ES. 1984. What is species selection? Systematic Zoology 33:318-328.

Vrba ES. 1985. Environment and evolution: Alternative causes of the temporal distribution of evolutionary events. South African Journal of Science 81:229-236.

Vrba ES. 1989. Levels of selection and sorting with special reference to the species level. Oxford Surveys in Evolutionary Biology 6:111-168.

Vrba ES. 1992. Mammals as a key to evolutionary theory. Journal of Mammalogy 73:1-28.

Vrba ES, Eldredge N. 1984. Individuals, hierarchies and processes: towards a more complete evolutionary theory. Paleobiology 10:146-171.

Vrba ES, Gould SJ. 1986. The hierarchical expansion of sorting and selection: sorting and selection cannot be equated. Paleobiology 12:217-228.

Yang W, Cerling TE, MacFadden BJ. 1994. Fossil horses and carbon isotopes: new evidence for Cenozoic dietary, habitat, and ecosystem changes in North America. Palaeogeography, Palaeoclimatology, Palaeoecology 107:2669-279.

Whittaker RJ, Ladle RJ, Araújo MB, Fernández-Palacios JM, Delgado JD, Arévalo JR. 2007. The island immaturity - speciation pulse model of island evolution: an alternative to the “diversity begets diversity" model. Ecography 30:321-327.

Wiley EO. 1981. Phylogenetics. New York: J. Wiley \& Sons.

Wiley EO, Lieberman BS. 2011. Phylogenetics, $2^{\text {nd }}$ edition. New York: J. Wiley \& Sons.

Wiley EO, Mayden RL. 1985. Species and speciation in phylogenetic systematics, with examples from the North American fish fauna. Annals of the Missouri Botanical Garden 72:596- 
635.

Yoder J, Clancey E, Des Roches S, Eastman J, Gentry L, Godsoe W, Hagey T, Jochimsen D, Oswald B, Robertson J. 2010. Ecological opportunity and the origin of adaptive radiations. Journal of Evolutionary Biology 23:1581-1596. 
Figure legends

Fig. 1. Any clade can be categorized somewhere within a two-dimensional space that emphasizes the role selection plays in driving diversification and the tempo of speciation. Only clades on the right hand side of the diagram are radiating, and further only clades in the lower right hand quadrant represent potential examples of adaptive radiation: the diversification in such clades still may be explicable by other phenomena. Clades in the upper right hand quadrant, although not adaptively radiating, constitute interesting phenomena in and of themselves and may be undergoing geographic radiation, where diversification is spurred by the taxon's presence in a geographically complex regions.

Fig. 2. Any clade situated in the lower right hand quadrant of Figure 1 can be more thoroughly categorized depending on whether the diversification is spurred by abiotic or biotic factors, whether the aptations are adaptive or exaptive in character, and whether selection is operating at the organism or species-level. Some examples are provided where appropriate. The box on the top left does not appear to constitute a viable phenomenon, and therefore is filled in with diagonal lines. Adaptive radiations driven by abiotic factors such as climate change may potentially be important, but have not been fully explored in the literature. 


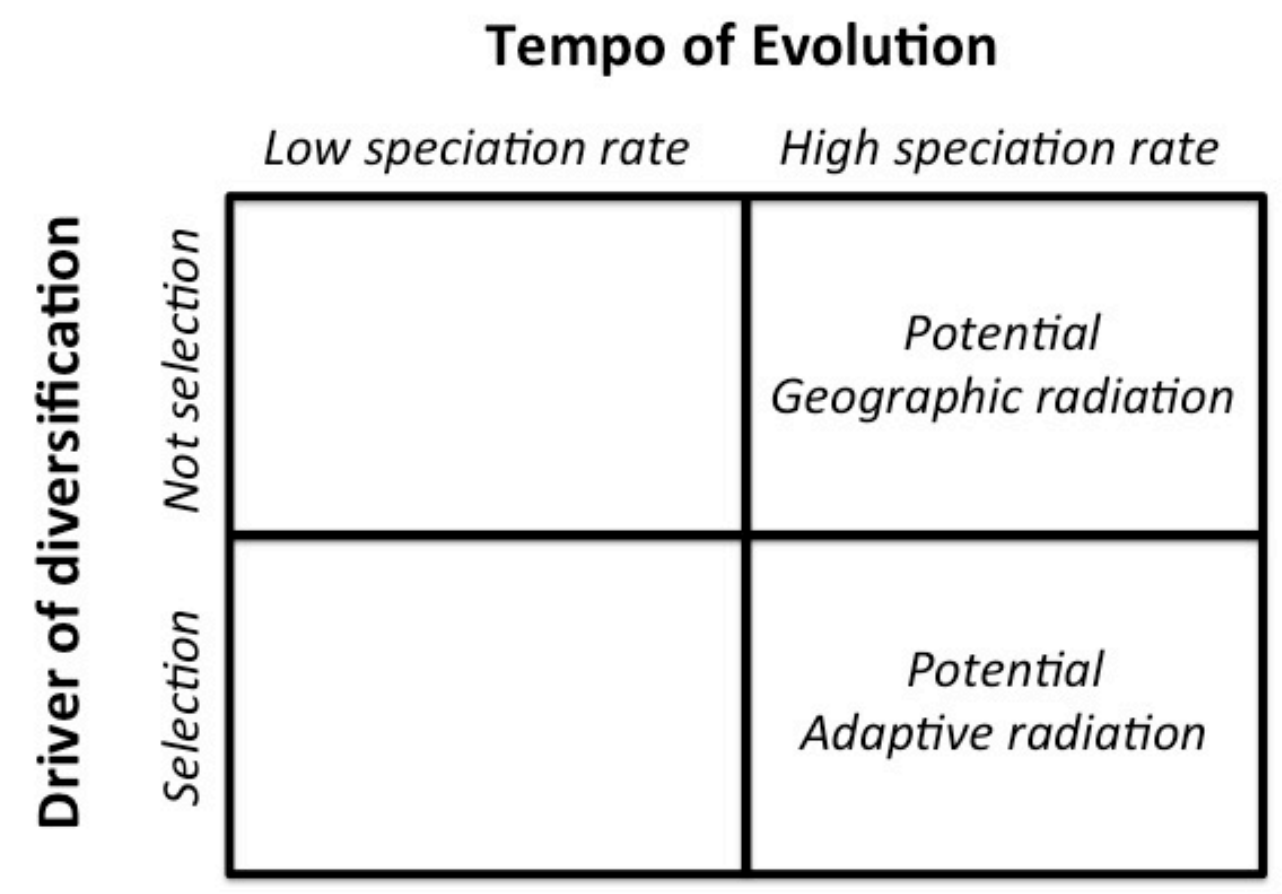

Figure 1 


\begin{tabular}{|c|c|c|}
\hline & Abiotic & Biotic \\
\hline $\begin{array}{l}\text { Exaptive - } \\
\text { Species level }\end{array}$ & 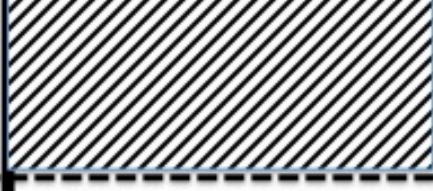 & $\begin{array}{l}\text { - Species selection } \\
\text { - snails, Zosterops }\end{array}$ \\
\hline $\begin{array}{l}\text { Exaptive - } \\
\text { Organism level }\end{array}$ & $\begin{array}{l}\text { Effect hypothesis } \\
\quad \text { - bovids } \\
\text { Horses }\end{array}$ & $\begin{array}{l}\text { Effect hypothesis } \\
\text { - Zosterops radiation }\end{array}$ \\
\hline Adaptive & $\begin{array}{c}\text { Radiations driven } \\
\text { by climate change } \\
\text {-? }\end{array}$ & $\begin{array}{c}\text { Radiations with } \\
\text { evidence of } \\
\text { ecomorphological } \\
\text { divergence } \\
\text { - sticklebacks, Anolis }\end{array}$ \\
\hline
\end{tabular}

Figure 2 